\title{
Glycogen and Protein Inclusions in Elongating Stipes of Coprinus cinereus
}

\author{
By G. PHILIP BLAYNEY AND ROGER MARCHANT \\ School of Biological and Environmental Studies, New University of Ulster, \\ Coleraine, County Londonderry, Northern Ireland
}

(Received 7 September 1976)

\begin{abstract}
SUMMARY
Coprinus cinereus stipes contain glycogen and protein inclusions. The amount of glycogen decreases during stipe elongation: it is at a maximum in stage III and falls to a minimum by stage V. Protein inclusions develop in stage II, reach their greatest size in stage III, and are degraded during stipe elongation in stages IV and V. The morphology of the glycogen differs in the two strains studied. Glycogen and insoluble protein are not evenly distributed throughout the stipe: glycogen is concentrated at the base while insoluble protein is concentrated at the top. During elongation the breakdown of both of these is greatest at the top of the stipe.
\end{abstract}

\section{INTRODUCTION}

The elongating stipe of the basidiomycete fruit body has provided experimental material for a number of studies in recent years. The rapid elongation of the stipe, raising the pileus and its spore-producing hymenium into a suitable position for spore dispersal, is an astounding process. Borriss (1934) accurately described the detailed developmental stages of the fruit body in Coprinus lagopus. Later work with other basidiomycetes has indicated an interdependence of cap and stipe in the elongation process, e.g., in Coprinus radiatus (Eilers, 1974) and in Agaricus bisporus and Flammulina velutipes (Gruen, 1963, 1969). In Coprinus cinereus (C. lagopus sensu Buller), Gooday (1974) and Cox \& Niederpruem (1975) have shown that excised stipes without caps will elongate autonomously, isolated from any vegetative mycelium or exogenous source of nutrients. Gooday (I972 $a$ ) had previously demonstrated the presence of active chitin synthetase in these elongating stipes and its inhibition and the concomitant inhibition of stipe elongation by polyoxin $\mathrm{D}$ (Gooday, $1972 b$ ). Further work has resulted in the extraction and partial purification of the chitin synthetase (Gooday \& de Rousset-Hall, I975; de Rousset-Hall \& Gooday, 1975). Clearly in these autonomously elongating excised stipes substantial reserve mobilization and synthetic processes must be occurring. Glycogen has already been established as a reserve polysaccharide in various parts of the fruit body during its development (Madelin, 1960; Matthews \& Niederpruem, 1973; McLaughlin, 1972, 1974) and it is an obvious candidate for a source of cell-wall precursor material. The present study was undertaken to examine the cytological changes which take place in the elongating stipe of $C$. cinereus and to try to relate these to biochemical events known to be taking place at the same time. 

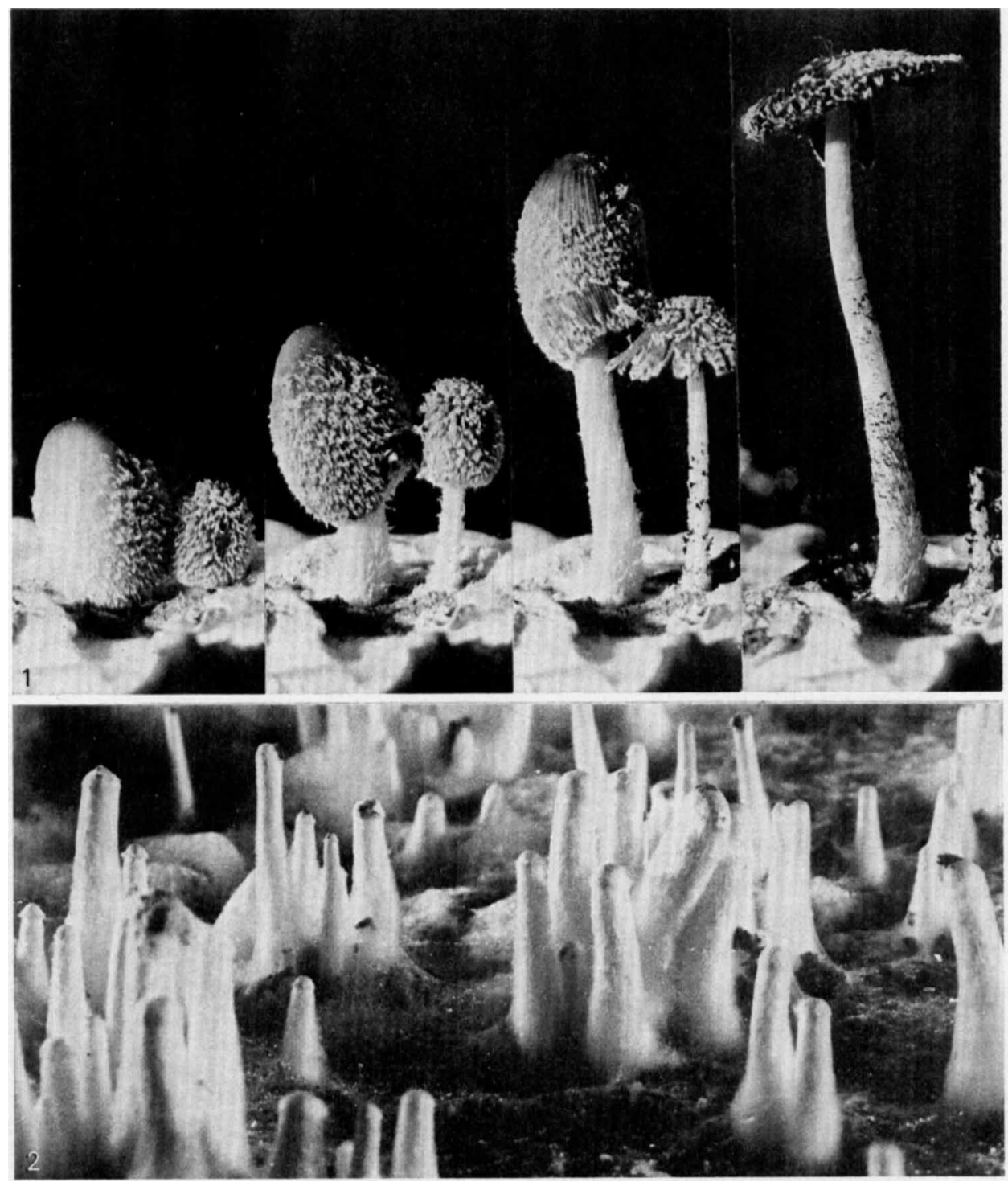

Fig. I. Developing fruit bodies of Coprinus cinereus $(\mathrm{TC} 4 \times \mathrm{H} 9$ ) showing the four stages of development used in this study: II, III, IV, V. The elongated stipes of stage V are 50 to $100 \mathrm{~mm}$ long.

Fig. 2. Pseudorhizal stipe bases of strain TC $4 \times$ H9 grown in darkness. The stipe bases grow as large as normal fruit bodies, i.e. up to $100 \mathrm{~mm}$.

\section{METHODS}

Organism. Two dikaryotic strains of Coprinus cinereus (Schaeff. ex Fr.) S. F. Gray were used: TC4 $\times$ H9 (mating types $\mathrm{A}_{5} \mathrm{~B}_{5} \times \mathrm{A}_{6} \mathbf{B}_{6}$ ) kindly provided by $\mathrm{Dr}$ Lorna A. Casselton, Queen Mary College, London; and C692 $\times$ MAEI3I (mating types $A_{3} B_{1} \times A_{6} B_{5}$ ) kindly provided by Dr G. W. Gooday, University of Aberdeen. Stock cultures were maintained on malt agar. Fruit bodies were obtained by inoculating aluminium boxes $(40 \times 30 \times 9 \mathrm{~cm})$ containing sterile commercial mushroom compost with actively growing malt-agar plates 
of the dikaryons macerated in distilled water. The boxes were each enclosed in a large polythene bag to retain moisture and incubated for 3 to 4 days at $30^{\circ} \mathrm{C}$ in the dark. The surface of the compost was then covered with a thin layer of sterile peat and the boxes were transferred to $20^{\circ} \mathrm{C}$ in the light. Fruit bodies appeared after 7 to 10 days. The resulting fruit bodies were classified into one of four stages (II, III, IV, V; Fig. I) according to the scheme of Borriss (1934). If the boxes were retained in darkness, the fruit bodies had an unusual appearance (Fig. 2). The cap and stipe initials remained small and were borne on a greatly elongated pseudorhizal stipe base (Buller, 1924). These stipe bases were_used in some parts of the study.

Electron microscopy. Small pieces of stipe from the various stages were fixed in acrolein and osmium by the method of Marchant (1975).

Cytochemistry. Certain polysaccharides were localized in thin sections using the periodate oxidation method of Thiéry (1967) as described by Marchant, Raudaskoski \& Shneyour (I976). This method produced heavy staining of glycogen in the sections.

Lipid was removed from sections using the sodium methoxide method of Eurenius \& Jarskär (1970) as modified by Marchant et al. (1976).

Protein was removed from sections using a pronase digestion (Monneron \& Bernhard, 1966). The origin of the pronase was Streptomyces griseus (Sigma) and it had a specific activity of 4 units $\mathrm{mg}^{-1}$. Sections were incubated in a $\mathrm{I} \%(\mathrm{w} / \mathrm{v})$ aqueous solution of pronase $\left(\mathrm{pH} 7 \cdot 4\right.$ ) for $24 \mathrm{~h}$ at $37^{\circ} \mathrm{C}$, washed in water and stained with lead citrate.

Preparation of extracts. The fresh stipe material was ground with a pestle and mortar in ice-cold buffer (Mcllvaine's buffer $\mathrm{pH}_{5} \cdot 6,0.05 \mathrm{M}-\mathrm{KH}_{2} \mathrm{PO}_{4}$ adjusted with $\mathrm{NaOH}$ ) added in the ratio $\mathrm{Io} \mathrm{ml}$ buffer to $\mathrm{I} \mathrm{g}$ fresh weight of stipe. The pulp was left in an ice bath for Io min with occasional stirring. Wall material and cell debris were removed by filtration through a glass-fibre filter, and the filtrate was centrifuged at $30000 \mathrm{~g}$ for $\mathrm{I} \mathrm{h}$. The pellet obtained was resuspended in buffer for the biochemical tests. The above procedure was carried out at o to $2{ }^{\circ} \mathrm{C}$.

Chemical estimations. Total hexose was determined by the anthrone method of Fairbairn (I953) and reducing sugars by the method of Dygert et al. (1965), both methods using glucose as standard. Protein was determined by the method of Lowry et al. (195I) using bovine serum albumin as standard. Glycogen was determined by the method of Krisman (1962) using oyster glycogen (Sigma) as standard.

\section{RESULTS}

\section{Cytological changes in elongating stipes}

Sections of the mid-portion of stipes of strain $\mathrm{TC}_{4} \times \mathrm{H} 9$ in the early stages of development (stages II and III) stained by the Thiéry method show large accumulations of glycogen (Fig. 3). The hyphae comprising the stipe contain a few small vacuoles within a dense cytoplasm. In the fully expanded stipes (Fig. 4) glycogen is almost totally absent and the hyphae contain large vacuoles within a sparse cytoplasm. These observations on the fluctuations in glycogen content are borne out by analyses of the carbohydrate in the $30000 \mathrm{~g}$ pellet obtained from the crude extract of whole macerated stipes (Table $\mathrm{I}$ ). The pellet contains large quantities of insoluble hexose, contaminated with only small amounts of reducing sugars. The amount of carbohydrate in the pellet, related to the fresh weight of stipe from which it was derived, is greatest in stage II and declines progressively to stage V. This result is in agreement with the ultrastructural observations.

A prominent feature of all stages of stipe development in strains TC4 $\times$ H9 and 

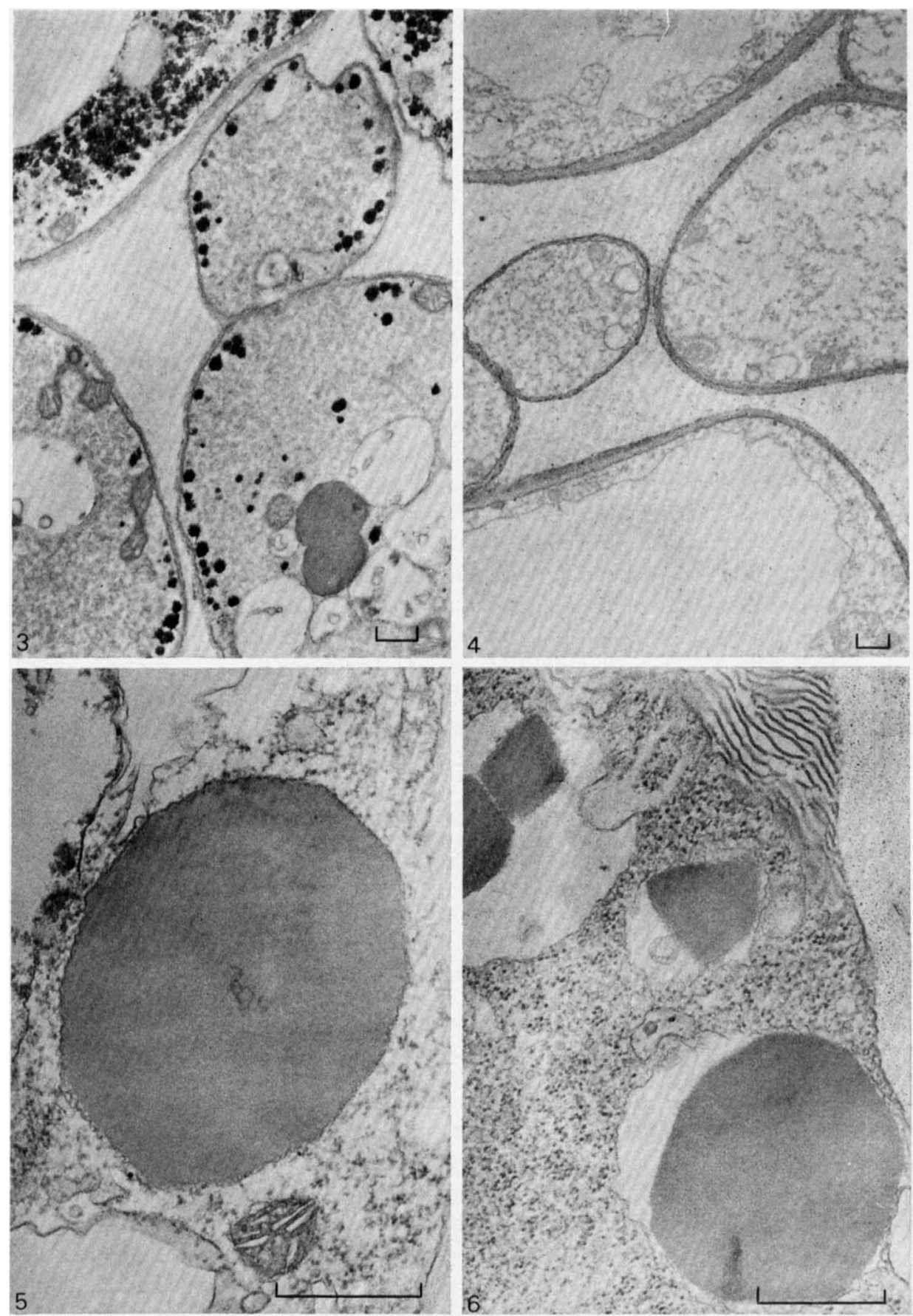

Bar markers represent $0.5 \mu \mathrm{m}$

Fig. 3. Cross-section of a stage III stipe of strain TC $4 \times$ H9 stained by the Thiéry method, showing glycogen rosettes.

Fig. 4. Cross-section of a stage V stipe of strain TC4 $\times \mathrm{H} 9$ stained by the Thiéry method, showing total absence of glycogen and the increased vacuolation.

Fig. 5. Protein inclusion in a stage III stipe of strain $\mathrm{TC} 4 \times \mathrm{H} 9$. Note the bounding membrane closely adhering to the inclusion.

Fig. 6. Protein inclusions in a stage V stipe of strain TC4 $\times$ H9. The inclusions lie free within the bounding membrane. 
Table I. Analysis of carbohydrates and protein in the $30000 \mathrm{~g}$ pellet from the crude extract of stipes of two strains of Coprinus cinereus

Results, expressed as $\mathrm{mg}$ ( $\mathrm{g}$ fresh $\mathrm{wt})^{-1}$, are mean values of duplicate assays.

\begin{tabular}{|c|c|c|c|c|c|c|c|c|}
\hline \multirow[b]{2}{*}{ Stage } & \multicolumn{4}{|c|}{$\mathrm{TC} 4 \times \mathrm{H} 9$} & \multicolumn{4}{|c|}{ C692 $\times$ MAEI $3 \mathrm{I}$} \\
\hline & $\ldots \mathrm{II}$ & III & IV & V & II & III & IV & V \\
\hline Total hexose & 10.6 & $4 \cdot 4$ & 3.8 & $I \cdot O$ & ND & ND & ND & ND \\
\hline Glycogen & ND & ND & ND & ND & $5 \cdot 2$ & $18 \cdot 3$ & $12 \cdot 8$ & $4 \cdot 5$ \\
\hline Reducing sugars & $\mathrm{I} \cdot 4$ & I.O & 0.8 & $\mathrm{I} \cdot 2$ & 0.8 & 0.8 & 0.6 & 0.6 \\
\hline Protein & $10 \cdot 0$ & $5 \cdot 6$ & $3 \cdot 3$ & $2 \cdot 2$ & $4 \cdot 4$ & $5 \cdot 2$ & $4 \cdot 7$ & $I \cdot 9$ \\
\hline
\end{tabular}

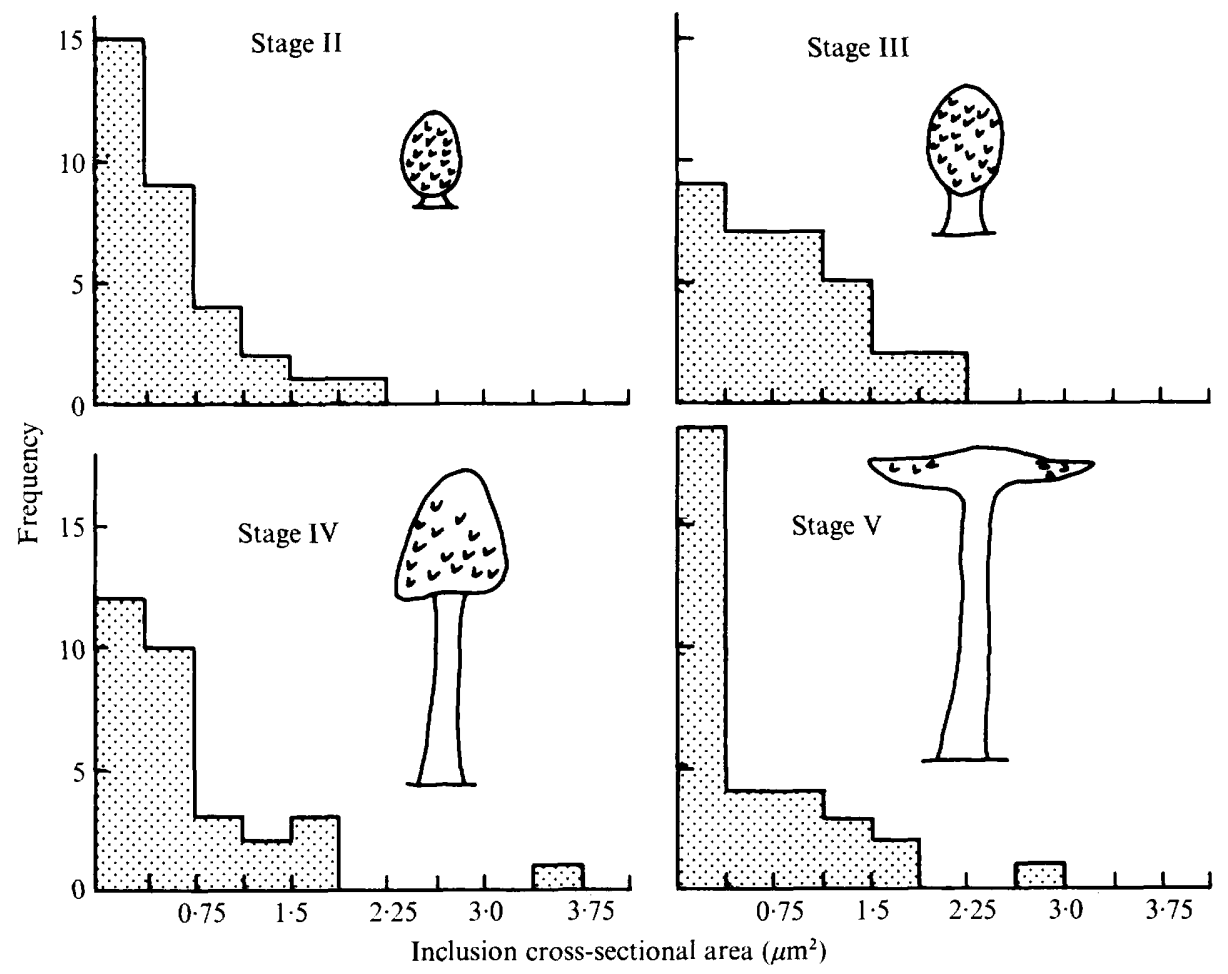

Fig. 7. Histograms showing the distribution of cross-sectional areas of protein inclusions in stipes of strain $\mathrm{TC} 4 \times \mathrm{H} 9$ at various stages.

C692 $\times$ MAEI3 I are large membrane-bounded inclusions with flattened faces (Fig. 5). In stage III stipes these inclusions appear to reach their maximum size, completely filling the enclosing membrane, while in the later stages (Fig. 6) they appear smaller and lie free within the enclosing membrane. This observation of apparent changes in the inclusions led us to photograph numbers of inclusions (approx. 30) at a standard magnification at each stage of stipe development. The cross-sectional area of each inclusion was measured from the photograph with a planimeter. If the assumption is made that inclusions are sectioned randomly then valid comparisons can be made. Histograms of the distribution of inclusion cross-sectional areas indicate that the inclusions increase in size from stage II to stage III and then progressively decline through stages IV and V (Fig. 7). 

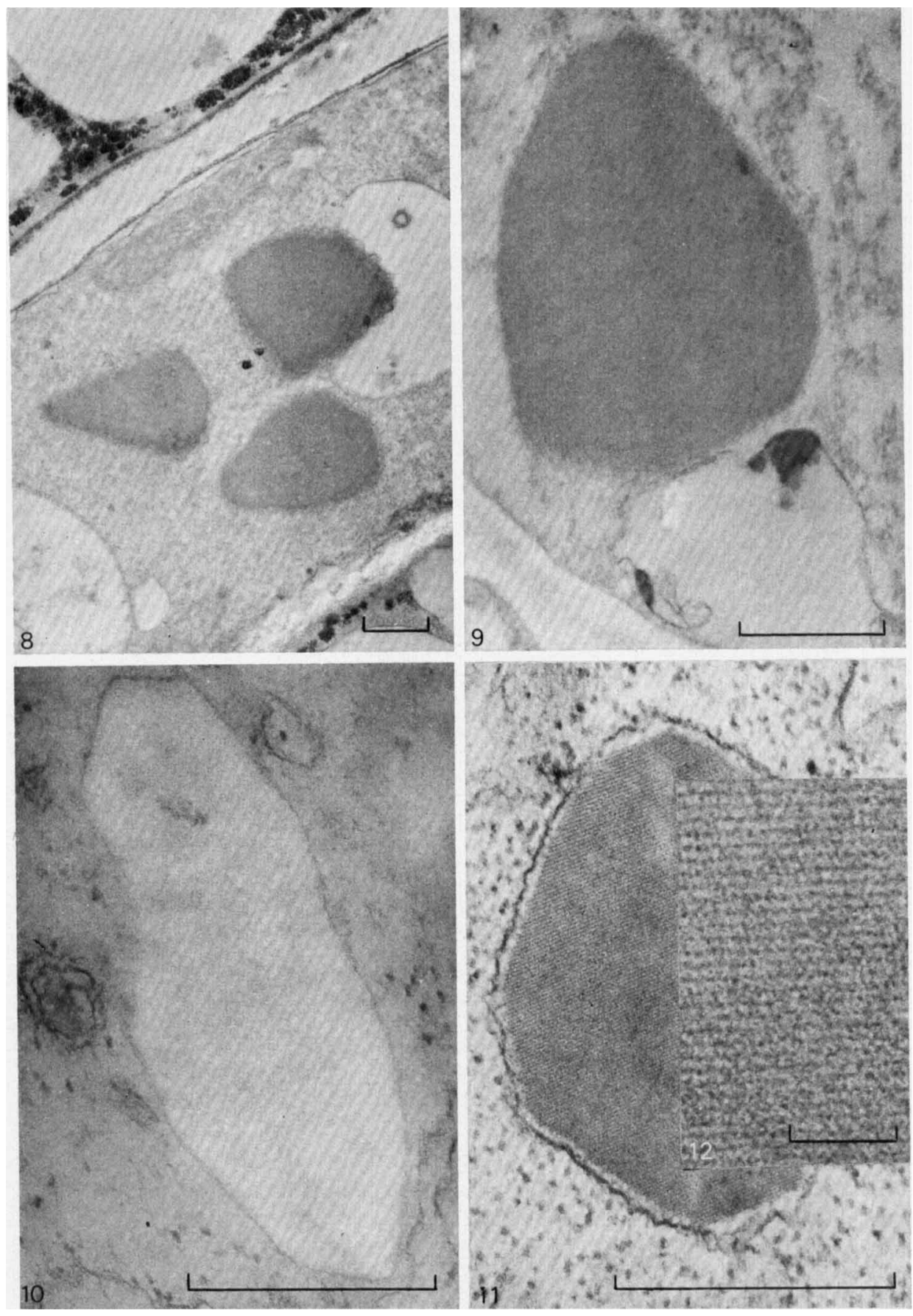

FIGUREs 8-12. For legends see facing page. 
Thiéry staining (Fig. 8) indicates that the inclusions do not contain large quantities of those polysaccharides susceptible to periodate oxidation. The inclusions are unaffected by sodium methoxide treatment (Fig. 9), indicating that they are probably not composed of lipid, but their bounding membranes are removed. Treatment of sections with the nonspecific protease, pronase, results in a substantial reduction in the subsequent lead staining (Fig. 10). The inclusions are therefore probably partly or wholly composed of protein. Protein inclusions also occur in the stipe bases of strain $\mathrm{TC} 4 \times \mathrm{H} 9$ grown in the dark (Fig. II). Here, however, they have a definite crystalline substructure (Fig. I2), possibly as a result of their less transient nature in the stipe base.

If the identification of the inclusions as proteinaceous is correct, then their pattern of change observed in the electron microscope would be expected to be reflected by analyses of insoluble protein in the $30000 \mathrm{~g}$ pellet from the crude extract. This is indeed so (Table I), with highest values for insoluble protein in the early stages declining to a minimum in stage V stipes.

\section{Strain comparisons}

In our work on Coprinus cinereus fruit bodies we used two different strains and have attempted to make some comparisons. In Thiéry-stained sections of strain C692 $\times$ MAEI3I (Fig. 13) there are no large visible aggregations of glycogen, even in early stage stipes, but only sparsely distributed material; there are, however, frequent, large, strongly staining membrane complexes (Fig. I4). Similar membrane complexes are found much less frequently in strain TC4 $\times$ H9 (Fig. 6), but glycogen aggregations are abundant. There is thus a substantial difference in the images obtained for the two strains. However, chemical analysis of the $30000 \mathrm{~g}$ pellet from the crude extract of strain C692 $\times$ MAEI3I (Table I) indicates that substantial amounts of glycogen are present and that the pattern of change is essentially similar to that in strain TC4 $\times$ H9. Strain $6692 \times$ MAEI $3 \mathrm{I}$ also has protein inclusions and the insoluble protein in the pellet declines in the later stage stipes in a similar manner to strain TC4 $\times$ H9. The stipe bases of both strains (Figs I5 and 16) contain glycogen but the cytological differences observed in the stipes also prevail, although to a lesser extent, in the bases.

\section{Distribution of glycogen and protein inclusions}

Attempts to quantify the distribution of glycogen and protein inclusions using electron microscopy were unsuccessful, but chemical analysis gave the patterns shown in Table 2. The highest concentration of glycogen is in the bottom of the stipes, but the greatest proportional changes occur in the upper parts where elongation takes place. In contrast, the insoluble protein is concentrated towards the top of the stipes, but again it is the upper parts of the stipe that show the greatest decline in insoluble protein during stipe expansion.

Figures 8-I2.

Bar markers represent $0.5 \mu \mathrm{m}$

Fig. 8. Inclusions in a stipe of strain $\mathrm{TC} 4 \times \mathrm{H} 9$ stained by the Thiéry method. Note the negative reaction of the inclusions in comparison with the glycogen.

Fig. 9. Inclusion in a stipe of strain $\mathrm{TC} 4 \times \mathrm{H} 9$ extracted with sodium methoxide. The bounding membrane of the inclusion and the plasmalemma have been removed, but vacuolar membranes are resistant to extraction.

Fig. Io. Inclusion in a stipe of strain $\mathrm{TC}_{4} \times \mathrm{H} 9$ treated with pronase. The staining material of the inclusion has been almost totally removed.

Fig. I I. Protein inclusion from the stipe base of strain $\mathrm{TC} 4 \times \mathrm{H} 9$, showing a crystalline substructure.

Fig. 12. Enlargement of part of Fig. I I, showing the crystalline substructure of the protein inclusion. (Bar marker represents $50 \mathrm{~nm}$.) 

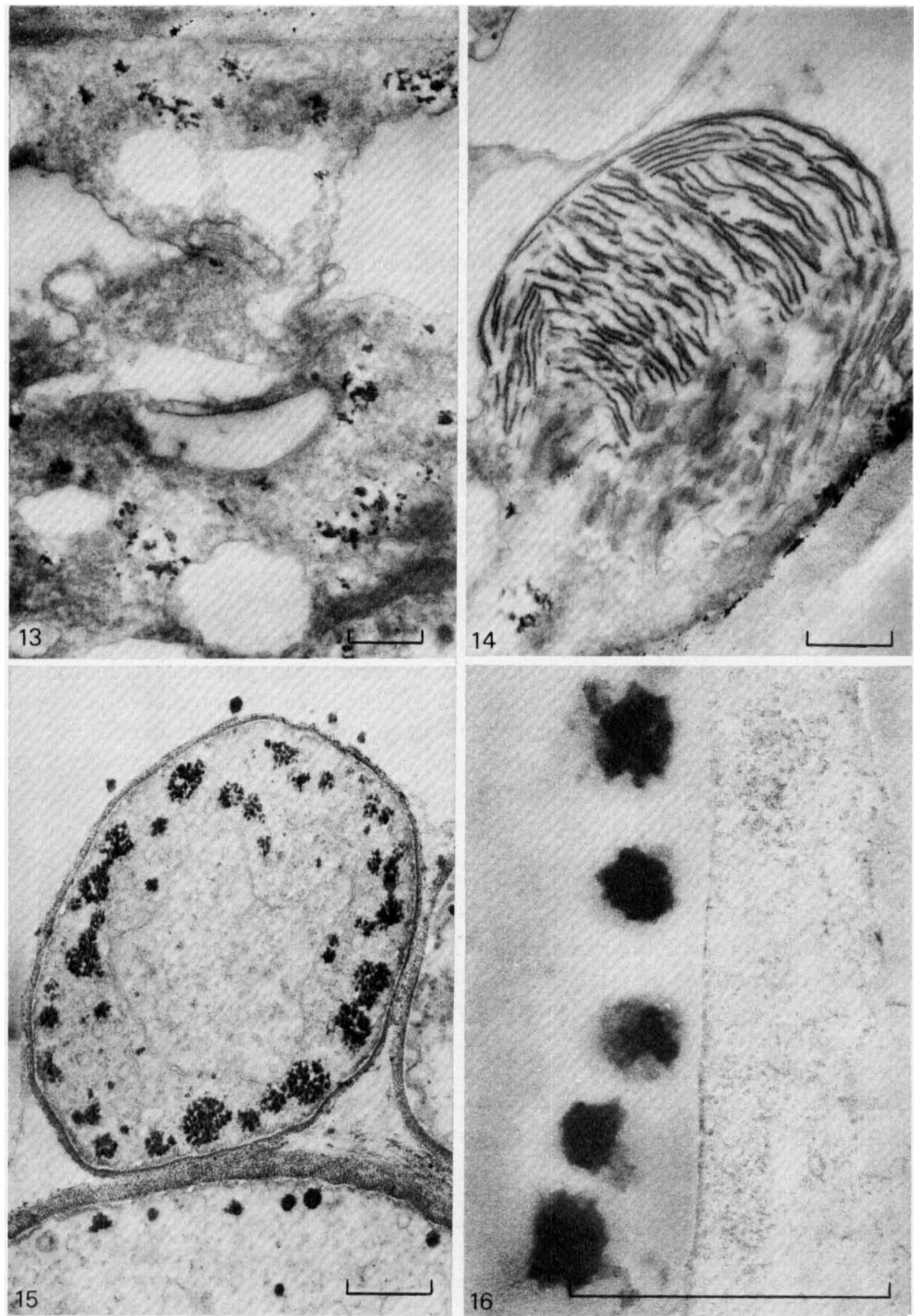

Bar markers represent $0.5 \mu \mathrm{m}$

Fig. I3. Cross-section of a stage II stipe of strain $6692 \times$ MAEI 3 I stained by the Thiéry method, showing only sparsely distributed positive-staining material.

Fig. I4. Membrane complex from a stage II stipe of strain $\mathrm{C} 692 \times$ MAEI 3 I stained by the Thiéry method. The membranes react strongly to this staining method.

Fig. 15. Cross-section of a stipe base of strain $\mathrm{TC} 4 \times \mathrm{H} 9$ stained by the Thiéry method, showing profuse glycogen rosettes.

Fig. I6. Cross-section of a stipe base of strain C692 $\times$ MAEI 3I stained by the Thiéry method, showing aggregations of glycogen without the typical rosette configuration. 
Table 2. Distribution of glycogen and protein in the $30000 \mathrm{~g}$ pellet from the crude extract of stipes of Coprinus cinereus strain C $692 \times$ MAEI 3 I at various stages

Stipes were divided into two equal portions for stages II and III and three equal portions for stages IV and V. Results, expressed as $\mathrm{mg}$ ( $\mathrm{g}$ fresh $\mathrm{wt})^{-1}$, are mean values from duplicate assays.

\begin{tabular}{|c|c|c|c|c|}
\hline \multirow[b]{2}{*}{ Glycogen } & \multicolumn{4}{|c|}{ Stage } \\
\hline & II & III & IV & V \\
\hline $\begin{array}{l}\text { Top } \\
\text { Middle } \\
\text { Bottom }\end{array}$ & $\begin{array}{l}0.92 \\
2 \cdot I\end{array}$ & $\begin{array}{l}0.54 \\
\text { I. } 3\end{array}$ & $\begin{array}{l}0.18 \\
0.18 \\
2.75\end{array}$ & $\begin{array}{l}0.11 \\
0.15 \\
\text { I.57 }\end{array}$ \\
\hline Protein & & & & \\
\hline $\begin{array}{l}\text { Top } \\
\text { Middle } \\
\text { Bottom }\end{array}$ & $\begin{array}{l}3 \cdot 9 \\
2 \cdot I\end{array}$ & $\begin{array}{l}4 \cdot 7 \\
I \cdot 84\end{array}$ & $\begin{array}{l}2 \cdot 2 \\
2 \cdot 2 \\
1 \cdot 3\end{array}$ & $\begin{array}{l}I \cdot 9 \\
1 \cdot 26 \\
2 \cdot 0\end{array}$ \\
\hline
\end{tabular}

\section{DISCUSSION}

Gooday (1974) has drawn attention to the differences between stipe extension in Coprinus cinereus and other basidiomycetes such as Agaricus and Flammulina (Gruen, 1967, 1969). In $C$. cinereus there is no evidence for a 'growth factor' controlling the rapid stipe elongation, nor is there any absolute requirement for translocation of exogenous materials into the elongating stipe. Gooday has termed this latter phenomenon an autonomous endotrophic process. Work with Coprinus radiatus (Eilers, 1974) has been interpreted as indicating the presence of a 'growth regulator' produced by the cap. In this case the cap is required for normal stipe development until the stipe reaches about a quarter of its final length. It is clear, therefore, that in $C$. cinereus at least, stipe elongation can be totally sustained endogenously. However, stipes in vivo increase in weight as they elongate yet do not become substantially more hydrated (only about $10 \%$ (unpublished results). The chitin synthesis observed by Gooday ( $1972 a$ ) in isolated elongating stipes requires a source of precursors to sustain it. It seems reasonable to suppose that the degraded glycogen may provide the source of sugar units, while it is possible that the nitrogen contained in the chitin molecule may be derived from the degraded protein inclusions.

Cox \& Niederpruem (I975) have shown that the stipe of C. cinereus elongates in particular regions only, principally in the upper portion. We have observed that the greatest decline in both glycogen and insoluble protein occurs in the upper portion of the stipe, which may indicate further correlation with the elongation process.

The form of the glycogen in the two strains is interesting since previous studies have indicated only the rosette type of configuration (McLaughlin, 1972, 1974; Matthews \& Niederpruem, 1973). In strain $\mathrm{TC}_{4} \times \mathrm{H}_{9}$ the rosette form is observed at each stage, while in strain C692 $\times$ MAEI3I typical glycogen rosettes appear neither in the stipe nor in the stipe base.

We thank Mr S. F. Lowry, Experimental Officer, University of Ulster Ultrastructure Unit, for his invaluable contributions to the completion of this work. We also thank Mr I. White of Dunderg Mushroom Farm for providing a supply of mushroom compost. The receipt of a postgraduate studentship to Philip Blayney from the Department of Education, Northern Ireland, is also gratefully acknowledged. 


\section{REFERENCES}

BorRIss, H. (1934). Beiträge zur Wachstums- und Entwicklungs-physiologie der Fruchtkörper von Coprinus lagopus. Planta 22, 28-69.

Buller, A. H. R. (1924). Researches on Fungi, vol. III. London: Longmans, Green and Co. (Reprinted by Hafner, 1958.)

Cox, R. J. \& NiEderpruem, D. J. (1975). Differentiation in Coprinus lagopus. III. Expansion of excised fruit bodies. Archives of Microbiology 105, 257-260.

Dygert, S., Li, L. H., Florida, D. \& ThOma, J. A. (1965). Determination of reducing substances with improved precision. Analytical Biochemistry 13, 367-374.

EILERS, F. I. (1974). Growth regulation in Coprinus radiatus. Archives of Microbiology 96, 353-364.

EURENIUS, L. \& JARSKÄR, R. (1970). A simple method to demonstrate lipids in epon-embedded ultrathin sections. Stain Technology 45, I 29-132.

FaIrbairn, N. J. (I953). A modified anthrone reagent. Chemistry and Industry 72, 86.

GoODAY, G. W. (1972a). The role of chitin synthetase in the elongation of fruit bodies of Coprinus cinereus. Journal of General Microbiology 73, xxi.

GoodAy, G. W. (1972 b). The effect of polyoxin D on morphogenesis in Coprinus cinereus. Biochemical Journal 129, 17-I8P.

Gooday, G. W. (1974). Control of development of excised fruit bodies and stipes of Coprinus cinereus. Transactions of the British Mycological Society 62, 391-399.

Gooday, G. W. \& DE Rousset-Hall, A. (1975). Properties of chitin synthetase from Coprinus cinereus. Journal of General Microbiology 89, I $37-145$.

Gruen, H. E. (1963). Endogenous growth regulation in carpophores of Agaricus bisporus. Plant Physiology $3^{8}, 652-666$.

GruEN, H. E. (1967). Growth regulation in fruit bodies of Agaricus bisporus. Mushroom Science 6, I03-I 20.

Gruen, H. E. (1969). Growth and rotation of Flammulina velutipes fruit-bodies and the dependence of stipe elongation on the cap. Mycologia 6r, 149-166.

Krisman, C. R. (1962). A method for the colorimetric estimation of glycogen with iodine. Analytical Biochemistry $\mathrm{I4}, \mathrm{I} 7-23$.

Lowry, O. H., Rosebrough, N. J., Farr, A. L. \& Randall, R. J. (I95I). Protein measurement with the Folin phenol reagent. Journal of Biological Chemistry 193, 265-275.

Madelin, M. F. (1960). Visible changes in the vegetative mycelium of Coprinus lagopus Fr. at the time of fruiting. Transactions of the British Mycological Society 43, 105-110.

MARCHANT, R. (I975). An ultrastructural study of 'phialospore' formation in Fusarium culmorum grown in continuous culture. Canadian Journal of Botany 53, $1978-1987$.

MARChANT, R., RAudASKoski, M. \& ShNeyour, Y. (I976). Ultrastructure of an indigotin-producing dome mutant of Schizophyllum commune. Journal of General Microbiology 96, 333-339.

Matthews, T. R. \& Niederpruem, D. J. (1973). Differentiation in Coprinus lagopus. II. Histology and ultrastructural aspects of developing primordia. Archiv für Mikrobiologie 88, 169-180.

MclaughuIn, D. J. (1972). Golgi apparatus in the postmeiotic basidium of Coprinus lagopus. Journal of Bacteriology Iro, 739-742.

McLAughLiN, D. J. (1974). Ultrastructural localization of carbohydrate in the hymenium and subhymenium of Coprinus. Evidence for the function of the Golgi apparatus. Protoplasma 82, 34I-364.

Monneron, A. \& Bernhard, W. (1966). Action de certaines enzymes sur des tissues inclus en epon. Journal de Microscopie 5, 697-7I4.

DE Rousset-Hall, A. \& GoodAy, G. W. (1975). A kinetic study of a solubilized chitin synthetase preparation from Coprinus cinereus. Journal of General Microbiology 89, I46-154.

THIÉRY, J-P. (1967). Mise en évidence des polysaccharides sur coupes fines en microscopie électronique. Journal de Microscopie 6, 987-1018. 